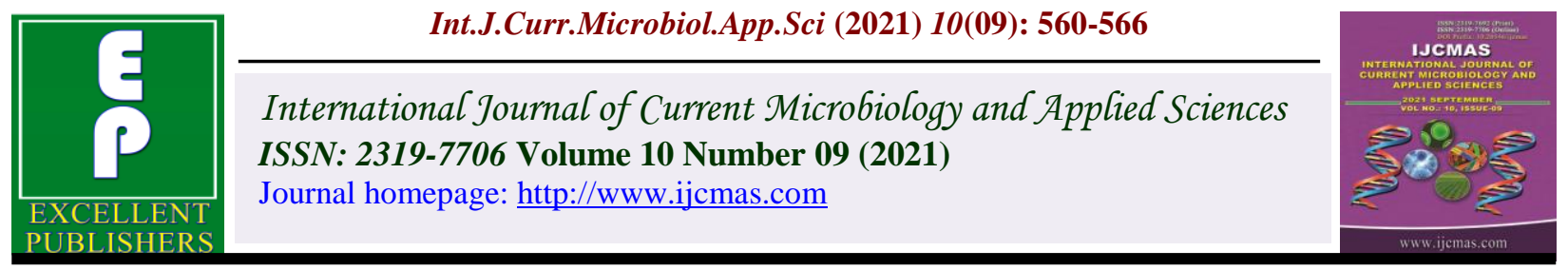

Original Research Article

https://doi.org/10.20546/ijcmas.2021.1009.064

\title{
Molecular Detection and Antimicrobial Susceptibility of Salmonella Species in Chickens
}

\author{
Gloria Sugun $^{1}$, Ehizibolo David ${ }^{2}$, Ebenezer Bukola Ogundejii ${ }^{2}$, Kaikabo Ahmed ${ }^{2}$, \\ Agada O. Godwin ${ }^{2}$, Benshak Audu ${ }^{2}$ and Sugun Manasa ${ }^{2 *}$ \\ ${ }^{1}$ No. 7 Vaccine Complex National Veterinary Research Institute Staff Quarters Vom \\ ${ }^{2}$ National Veterinary Research Institute Vom Plateau State Nigeria \\ *Corresponding author
}

\section{A B S T R A C T}

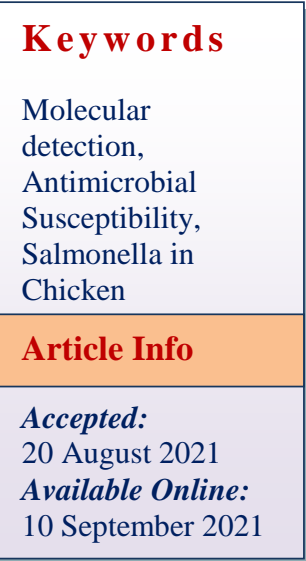

The study was intended for molecular detection of Salmonella Spp isolated from chicken. A total of 160 samples comprising of 40 liver, 40 spleen, 40 lungs and 40 intestines were collected directly into buffered peptone in universal bottles at the poultry slaughter houses of the four districts in Jos South Local Government area of Plateau State. The samples were enriched in $10 \mathrm{ml}$ of Rappaport-Vassiliades broth and cultured onto Xylems Lysine Deoxycholate (XLD) agar for the isolation of bacteria. The isolated bacteria were identified by studying staining characteristics, cultural properties on different selective media, biochemical tests, catalase and coagulase test, and finally by PCR. Out of 160 samples, 65 (41\%) samples were found positive for Salmonella Spp on XLD and 24 (37\%) positive by biochemical analysis. Two(2) Salmonella isolates were amplified by $942 \mathrm{bp}$ gene based PCR. Antimicrobial sensitivity test was carried out to ascertain the susceptibility of the organism to various antibiotics. Its results showed that the Salmonella isolates were resistant to amoxycillin (100\%) and erythromycin (100\%), gentamicin (100\%), Clindamycin (100\%) streptomycin (100\%), tetracycline $(100 \%)$, sulphamethoxazole/trimethoprim (100\%) but sensitive to Ceftiofur (100\%).

\section{Introduction}

Salmonellae are Gram-negative facultative anaerobic rod-shaped bacteria that measure 0.7-1.5 by 2.0-5.0 $\mu \mathrm{m}$, non-sporogenic. Salmonella species have been considered as one of the most important foodborne pathogens around the world. Salmonellae are gram negative; non-lactose fermenting and non-sporing bacteria with exception of $S$. pullorum and $S$. gallinarum, all salmonellae are actively motile (Cheesbrough et al., 2016).

Salmonella are widely distributed in nature and survive well in a variety of foods and contamination can occur at multiple steps 
along the food chain (Pui et al., 2011). Many epidemiological studies have reported the wide variety of routes by which Salmonella can be disseminated within integrated poultry farms and across geographical areas in different countries at different times (Norgrady et al., 2014). Infection with Salmonella can occur through inadequate cleaning and disinfection of poultry houses, presence of contaminated carriers especially rodents and insects, litters, water, dust, equipment and feed (Carrique-Mas et al., 2008). Infection in day-old chicks could be vertical from infected breeder flocks or horizontally transmitted during hatching, loading and transporting to the farm (Chriel et al., 2017).

In 2011, Nigerian hen egg production totalled 636,000 metric tons (MT) and was valued at 8527.49 million, ranking $19^{\text {th }}$ in world hen egg production and the stop producer in Africa (FAO, 2012). Both large and small egg farms are scattered all over the country, although they are generally concentrated around the major urban centres (FAO, 2012). Poultry meat is one of the major sources of animal protein in Nigeria like in many developing countries because of its affordability and acceptability (Bettridge et al., 2014). This source of protein is however being threatened by diseases such as salmonellasis and avian influenza (FAO, 2012). Poultry salmonellosis remains a major constrain to poultry production in all part of Nigeria. The aim of this study was to detect and characterize Salmonella spp. in commercial chicken in Jos South Local Government area of Plateau state.

\section{Materials and Methods}

\section{Study location}

The study was conducted in Jos-South Local Government area of Plateau State Nigeria. Jos-South with its headquarter at Bukuru $9^{0}$
$4800 " \mathrm{~N} 8^{0} 5200$ " E. It has an area of $510 \mathrm{~m}^{2}$ and population of 306,716 as at the 2006 census (Rim, 1993). The study covered Kuru, Vwang, Kugiya and Gyel.

\section{Sample collection}

A total of 160 samples comprising of 40 liver, 40 spleen, 40 lungs and 40 intestines were collected directly into buffered peptone in universal bottles at the poultry slaughter houses of the four districts in Jos South Local Government area of Plateau State. All samples were transported on ice to Salmonella laboratory bacterial research for analysis.

\section{Isolation of Salmonella}

Bacterial culture and identification were carried out in the Salmonella laboratory National Veterinary Research Institute Vom. Tissue samples of the organs liver, spleen, lungs and intestine were enriched in $10 \mathrm{ml}$ of Rappaport-Vassiliades broth (Oxoid Basingstoke, UK)). Following the enrichment, samples were incubated at $37^{\circ} \mathrm{Cfor} 24$ hours. Using a sterile wire loop, a loopful of each incubated broth culture were inoculated onto Xylose Lysine Deoxycholate (XLD) agar (Oxiod, Basingstoke, UK) and incubated at $37^{\circ} \mathrm{C}$ for 24 hours. The plates were examined for typical colonies of Salmonella. The colonies from the plates were further subcultured on XLD agar and incubated at $37^{\circ} \mathrm{C}$ for 24 hours. The plates from the sub cultured plates were observed for typical colonies of Salmonella as described suspected colonies were subjected to, urease, and triple sugar iron TSI Doughlas et al., (1998).

\section{Phenotypic Identification of Salmonella}

Pure colonies of Salomonella were picked up from XLD plate with bacteriological loop, emulsified with a drop of distilled water on a clean greasy-free slide and fixed by gentle 
heating. Crystal violet was applied on each smear to stain for 1 minute and then wash with water. Then Lugols iodine was applied for 1 minute and again wash with water.

This was followed by addition of $95 \%$ alcohol which served as decolourizer and allowed to stand for a period of 10 seconds. After rinsing with water, safranin was used to counter stain and then washed with water after 30 seconds.

The preparation was air dried and examine under the microscope with high power objective (X100) using oil immersion Doughlas et al., (1998).

\section{Molecular detection of Salmonella}

A set of primer pair specific for the invAgene for Salmonella species with sequences base pair 942bp was used (Galán et al., 1992). Primer sequences: invAf5-3 ${ }^{1}$ - GTG AAAT TATC GCCA CGTTCGGGCAA and invAr5$3^{1}$ - TCA TCGC ACCG TCAA AGGAACC.

\section{Antibiotic susceptibility test of Salmonella} isolated from commercial chickens

All the isolates were tested for antibiotic susceptibility using Kirby-Bauer et al., 1966 diffusion assay. The antibiotic be tested includes, Tetracycline $30 \mu \mathrm{g}$, Amoxycillin $25 \mu$, sterptomycine $10 \mu \mathrm{g}$, sulphamethoxazole trimethoprime $25 \mu \mathrm{g}$, Ceftiofur $30 \mu \mathrm{g}$.

The inhibition zone around each was measured independently and compared with standard interpretive charts: Clinical Laboratory Standard Institute (CLSI, 2006). Zone size for each antimicrobial agent was measured independently before comparison.

\section{Results and Discussion}

Isolation of Salmonella from various locations in the study area

From a total of 160 samples subjected to bacteriological examination on XLD. The distribution of Salmonella isolated from various locations in the study area is presented (Table 1).

\section{Salmonella isolated from different sample types}

Higher percentage $(45 \%)$ of gram negative bacteria suspected to be salmonella were isolated from the intestines in comparison to other organs.

\section{Biochemical characteristics of Salmonella spp}

The results of the phenotypic analysis of the isolated gram negative bacteria suspected to be salmonella. Thirty-seven percent (24/65) of the isolates were positive for the biochemical tests performed.

\section{Molecular confirmation of Salmonella isolated from commercial chicken in Jos South}

The result of the molecular confirmation of salmonella isolates using specific oligonucleotide primers by PCR is shown in Table 4. Out of the 24 initial suspected salmonella isolates stored on nutrient agar slant, only 6 could be revived for molecular confirmation (four from Kugiya and 2 from Kuru district), of which 2 isolates from Kugiya district (33\%) tested positive by PCR. 
Table.1 Salmonella isolated from various locations in the study area

\begin{tabular}{|c|c|c|}
\hline Location & No of samples & No of positive samples on XLD \\
\hline Kugiya & 40 & $23(58 \%)$ \\
\hline Kuru & 40 & $19(48 \%)$ \\
\hline Vwang & 40 & $9(23 \%)$ \\
\hline Gyel & 40 & $14(35 \%)$ \\
\hline Total & 160 & $65(41 \%)$ \\
\hline
\end{tabular}

Table.2 Salmonella isolated from different sample types.

\begin{tabular}{|c|c|c|c|c|c|}
\hline & \multicolumn{4}{|c|}{ No of sample type positive } & \\
\hline Location & Liver & lungs & spleen & Intestine & Total \\
\hline Kugiya & 5 & 7 & 6 & 5 & $23(58 \%)$ \\
\hline Kuru & 6 & 5 & 4 & 4 & $19(48 \%)$ \\
\hline Vwang & 2 & 2 & 1 & 4 & $9(23 \%)$ \\
\hline Gyel & 3 & 1 & 5 & 5 & $14(35 \%)$ \\
\hline Total & $16(40 \%)$ & $15(38 \%)$ & $16(40 \%)$ & $18(45 \%)$ & $65(41 \%)$ \\
\hline
\end{tabular}

Table.3 Biochemical characteristics of Salmonella spp isolated from chickens in the study area

\begin{tabular}{|c|c|c|c|c|}
\hline & & \multicolumn{2}{|c|}{ Biochemical analysis } & \\
\hline Location & No of isolates & TSI & Urease & No and percentage of positive \\
\hline Kugiya & 23 & 12 & 11 & $11(48 \%)$ \\
\hline Kuru & 19 & 13 & 10 & $10(53 \%)$ \\
\hline Vwang & 9 & 5 & 2 & $2(22 \%)$ \\
\hline Gyel & 14 & 3 & 1 & $1(7 \%)$ \\
\hline Total & 65 & & & $24(37 \%)$ \\
\hline
\end{tabular}

Table.4 Results of the molecular confirmation of salmonella isolates in Jos South LGA using PCR

\begin{tabular}{|c|c|c|}
\hline Location & No isolates & No of PCR positive \\
\hline Kugiya & 4 & 2 \\
\hline Kuru & 2 & 0 \\
\hline Total & 6 & 2 \\
\hline
\end{tabular}


Table.5 Antibiotic susceptibility profile of confirmed salmonella isolates in Jos South LGA

\begin{tabular}{|c|c|c|c|}
\hline Antimicrobial agents & Concentration $\boldsymbol{\mu g}$ & No. of strain resistant & No. of strain sensitive \\
\hline Gentamycin & 10 & 2 & 0 \\
\hline Sulphamethoxazole/trimethoprim & 25 & 2 & 0 \\
\hline Tetracycline & 30 & 2 & 0 \\
\hline Erythromycin & 5 & 2 & 0 \\
\hline Amoxicillin & 25 & 2 & 0 \\
\hline Streptomycin & 10 & 2 & 0 \\
\hline Ceftiofur & 30 & 0 & 2 \\
\hline Clindamycin & 2 & 2 & 0 \\
\hline
\end{tabular}

Fig.1 Shows the result of agarose electrophoresis of the positive salmonella amplicons detected by PCR in Kugiya district, Jos South LGA

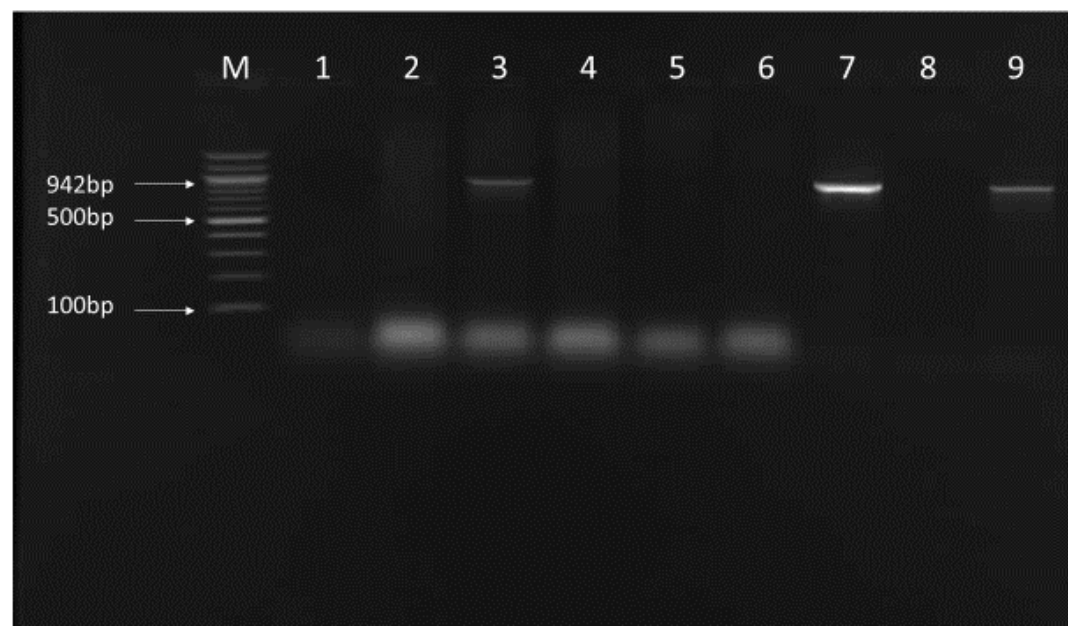

Confirmation of Salmonella isolates in Jos South LGA using PCR: Positive samples at 942bp. Lanes: M= Maker, 9= positive control, $8=$ negative control, 3 and $7=$ positive samples, $4,5,6=$ negative samples

Plate.1 The zone of inhibition observed from the disc sensitivity test is shown in Plate 1.

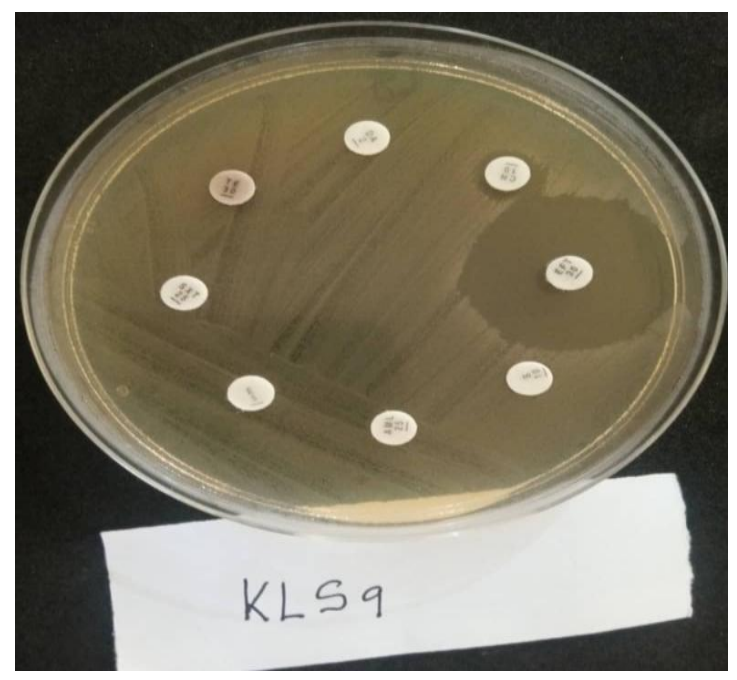




\section{Antibiotic susceptibility test}

The antibiogram of the confirmed salmonella isolates to eight different antibiotics is shown. The confirmed salmonella were found to be resistant to all antibiotics used except ceftiofur® (EFT). The zones of inhibition observed from the disc sensitivity test is shown in Plate 2.

Salmonellosis is a major public health concern and continues to have a serious economic importance in the poultry industry in all countries (Morales and McDowell, 1999). Broilers meat and raw poultry products are considered to be a reservoir of infection to human where Salmonella food poising in human is often associated with the consumption of poultry products (Coyle et al., 1988; Olsen et al., 2000). The present study was conducted to investigate the incidence of salmonella species in chicken. All collected samples in the study area were cultured first in XLD. Kugiya district of Jos South LGA had the highest numbers of gram negative bacteria suspected to be Salmonella 58\% and $48 \%$ respectively. The rate of suspected Salmonellain Kugiya district was $(58 \%)$ in this study was comparable to that reported in other studies. Yagoub and Mohamed (1987) examined 1488 samples in the Sudan and isolated 58 Salmonella which comprised 3.9\% of the total isolates. In another study, Ezdihar(1996) examined 610 samples from poultry in the Sudan and isolated 45 Salmonella which counted for $7.4 \%$ of the total isolates. The later study showed higher isolation rate compared to the finding of this study and that might be attributed to the large difference in the number of samples collected in both studies.

In the phenotypic analysis of Salmonella isolates, thirty seven percent $24 / 65$ of the isolates were positive to biochemical test. Out of the thirty-four initial isolates stored on nutrient agar slant only six could be revived for molecular analysis where two isolates were confirmed to be Salmonella.

The isolates that were confirmed were further tested for their senility to eight different types of antibiotics. Only one antibiotic Cefttiofur was sensitive to both isolates the remaining seven were $100 \%$ resistant.

Two salmonella isolates were detected in Kugiya district of Jos South Local Government Area even though theywere found to be sensitive to the antibiotic ceftiofur ${ }^{\circledR}$ they also showed resistance to the other antibiotics tested (Table).

The present study recommend strict hygienic practices to minimize salmonella infection in poultry farm. Similarly, we advocate that poultry products should be properly washed and cooked before consumption to safeguard human health from infection with salmonella from foods of poultry origin.

\section{References}

Ashton, W. L. G. (2015). Enterobacteriaceae. In: F. T. W. Jordon, ed. Bailliere Tindall, Philadelphia. Pp: 11-41.

Bauer, A. W.; Kirby, W. M.; Sherris, J. C. and Turck, M. (1966). Antibiotic susceptibility testing by standardized single disc method. American Journal of Clinical Pathology, 45: 493-496.

Coyle, E. F.; Plamer, S. R.; Ribeiro, C. D.; Jones, H. I.; Howard, A. J.; Ward, L. and Rowe, B. (1988). Salmonella enteritidis phage type 4 infection: Association with hen's eggs. Lancet, 86: 1295-1297.

Yagoub, I. A. and Mohamed, T. E. (1987). Isolation and Identification of Salmonella from chickens in Khartoum province of the Sudan. Britain Veterinary Journal, 143: 537-540. 
Galán J E, Ginocchio C, Costeas P. Molecular and functional characterization of the Salmonella invasion gene invA: homology of InvA to members of a new protein family. $J$ Bacteriol1992; 174:4338-49.

Clinical and Laboratory Standards Institute (CLSI), 2006. Performance Standards for Antimicrobial Susceptibility Testing; Sixteenth Informational Supplement. 940

Doughlas W W, Gast R K, Mallinson E T. Salmonellosis. In: Swayne D E, Glisson J R, Jackwood M W, eds. A Laboratory manual for the isolation and identification of avian pathogens. 4 edn: American Association of Avian Pathologists, Kennett Square, ennsylvania, 1998:4-13.

Ezdihar, A. A. (1996). Isolation and characterization of Salmonella from domestic fowl and its environment in the state of Kordofan. Master of Veterinary Science. University of Khartoum. Sudan.

Bettridge J. M., Lunch S. E., Brena, M. C., Melese, K., Dessie, T., Terfa, Z. G., Desta, T. T, Rushton, S., Hanotte, O., Kaiser, P., Wigey, P., Christley, R. M (2014). Infection interactions in Ethiopian village chickens. Preventive Veterinary Medicine. 117: 358-366.

Carrique-Mas, J. J, Breslin, M;, Snow, L.C, McLaren, I, Sayers, A. R, and Davis, R. H (2008). Persistance and clearance of different Salmonella serovars in buildings housing layer hen. Epidemiology and Infection, 19: 1-10. Cheesbrough, M. (2016). District Laboratory
Practice in Tropical Countries, 3 rded Chriel, M., Stryhn, H., Dauphin, G (2017). Generalized linear mixed model's analysis of risk factors for contamination of Danish broiler flocks with Salmonella typhimurium. Preventive Veterinary Medicine, 40: 117.

Food and Agricultural Organization (FAO) (2012). Assessment of the Nigerian poultry market chain to improve biosecurity.

Puiet, C. F., Wong, L. C., Chai, R., Tenung, P., Jeyaletchumi, M. S., Noor, H. A., Ubong, M. G, Farinazleen, Y. K., Son, R. (2011). Salmonella: foodborne pathogen. International Food Research Journal. 18: 465-473.

Norgrady, N., Imre, A., Rychlik, I., Barrow, P. A., Nagy, B. (2014). Growth and colonization suppression of Salmonella enterica serovar Hadar in vitro and in vivo. FEMS Microbiology Letters. 218: $127-133$.

Olsen, S. J.; Machinnon, L. C.; Goulding, J. S.; Been, N. H. and stusker.; L. (2000). Surveillance for food borne disease. outbreaks in United States Of America (1993-1997). 49: 1-62.

Research in Motion (RIM, 1993). Nigerian Livestock resources. Four volume report to the Federal Government of Nigeria. Submitted by Resource Inventory Management Limited. 1. Executive Summary and Atlas. 2. National synthesis. 3. State. 4 Urban Report and Commercially Managed Livestock Survey Report.

\section{How to cite this article:}

Gloria Sugun, Ehizibolo David, Ebenezer Bukola Ogundejii, Kaikabo Ahmed, Agada O. Godwin, Benshak Audu and Sugun Manasa. 2021. Molecular Detection and Antimicrobial Susceptibility of Salmonella Species in Chickens. Int.J.Curr.Microbiol.App.Sci. 10(09): 560566. doi: https://doi.org/10.20546/ijcmas.2021.1009.064 